$++t+t+t+t+t+t+t++t++t$

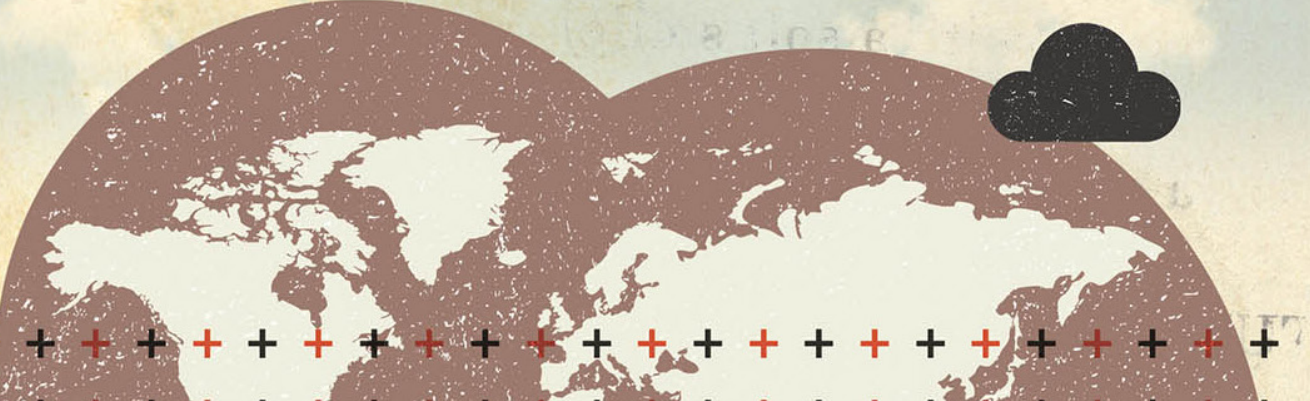
$t+t+t+t+t+t+t+t+t+t+t+t+$
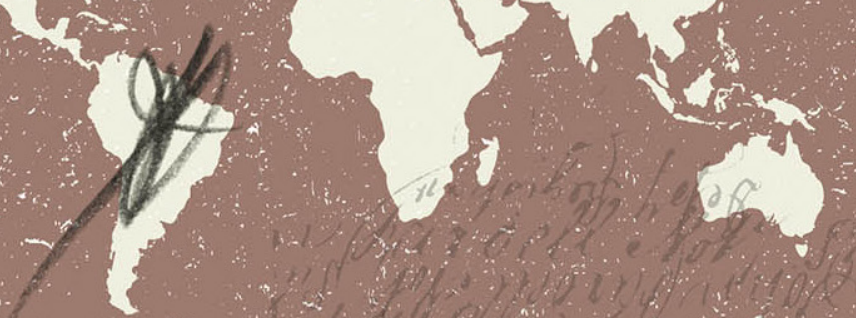

$++4++t++++4+4++4++4+4+++$
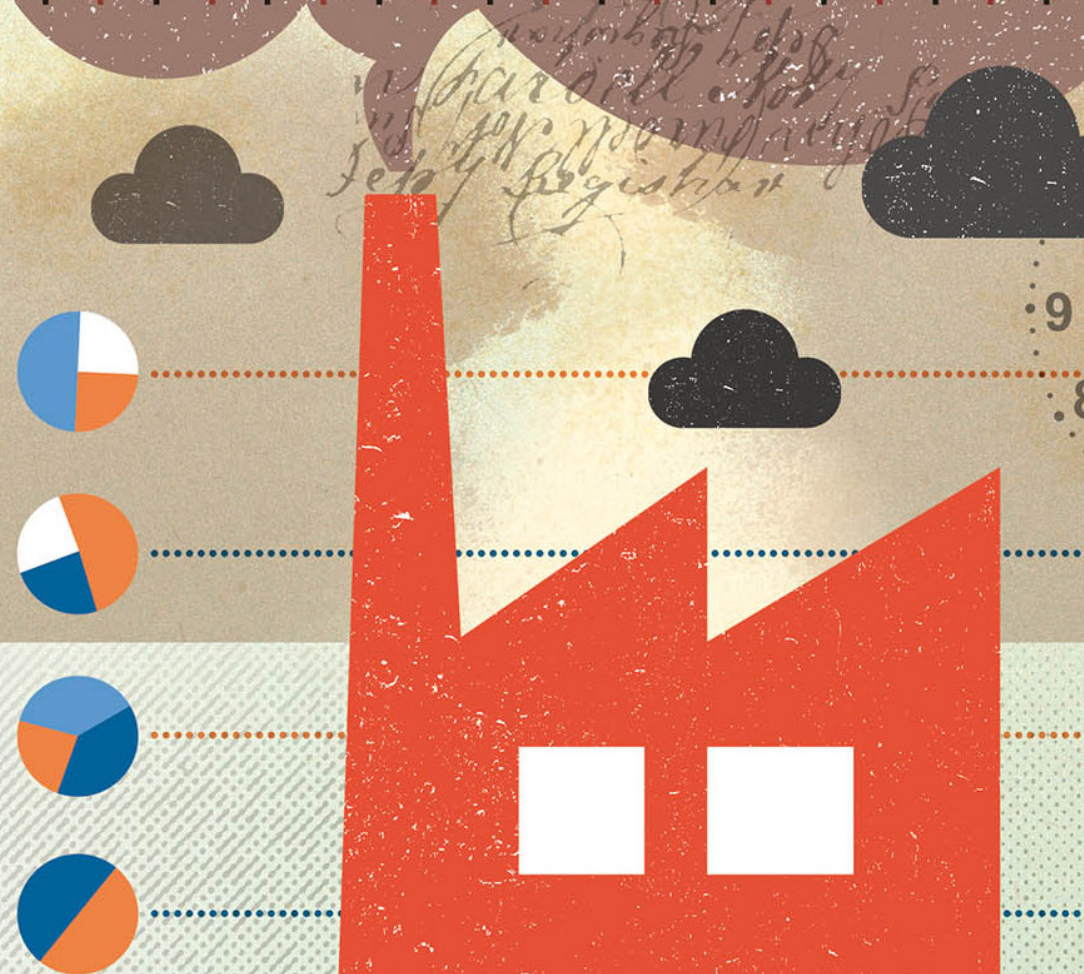

1112 


\title{
Avaliação da dimensão social no Protocolo de Kyoto
}

\author{
Assessment of social dimension in Kyoto \\ Protocol
}

\author{
* Nathalia Machado Simão \\ ** Gilberto Martins \\ ${ }^{* * *}$ Arilson Forvoreto
}

\section{Resumo}

Este artigo tem como principal objetivo apresentar a abrangência do conceito de adicionalidade e relacioná-lo à dimensão social no Protocolo de Kyoto e nos projetos de biogás de aterro sanitário do Mecanismo de Desenvolvimento Limpo aprovados no Brasil. A partir da exposição da abordagem das capabilities de Amartya Sem (2001) e do estudo dos indicadores sociais questiona-se a efetiva importância que se dá à dimensão social nas avaliações para a aprovação dos projetos no Mecanismo de Desenvolvimento Limpo. Verificou-se que não há métodos formais para a avaliação desta dimensão no Protocolo de Kyoto tampouco nos projetos do estudo empírico em questão e dessa forma as avaliações assumem caráter subjetivo, visto que não existem exigências mínimas muito menos critérios classificatórios ou eliminatórios definidos.

Palavras-chave: Adicionalidade; Dimensão Social, Mecanismo de Desenvolvimento Limpo, Protocolo de Kyoto, Metodologias de Avaliação dos Projetos.

\begin{abstract}
This paper has as its main objective to present the scope of the concept of additionality and relate it to the social dimension in the Kyoto Protocol and in landfill biogas destruction projects approved by the CDM in Brazil. From the exposure of the capabilities approach of Amartya Sen (2001) and the study of social indicators the actual importance given to the social dimension in evaluations for the approval of projects in Clean Development Mechanism is questioned. It was observed that there are no formal methods for the evaluation of this dimension in the Kyoto Protocol nor in the empirical study on the projects in question, so the evaluations assume a subjective character, since there are no minimum requirements neither classificatory or eliminatory criteria defined.
\end{abstract}

Keywords: Additionality; Social Dimension, Clean Development Mechanism, Kyoto Protocol, Methodologies for the Evaluation of Projects.

\footnotetext{
* Doutora em Energia pela Universidade Federal do ABC. Professora e consultora da empresa Posglobal Treinamentos. Email: nathalia.simao@posglobal.com.br

** Diretor do Centro de Engenharia, Modelagem e Ciências Aplicadas (CECS) da Universidade Federal do ABC (UFABC).E-mail: gilberto.martins@ufabc.edu.br

*** Coordenador do Bacharelado em Ciências e Humanidades e membro do Centro de Engenharia, Modelagem e Ciências Aplicadas (CECS) da Universidade Federal do ABC (UFABC). E-mail: arilson.favareto@ufabc.edu.br
} 


\section{Introdução}

Na proposta defendida pela Convenção do Clima e pelo Protocolo de Kyoto, as ações que visam o controle de emissões dos gases de efeito estufa têm como um dos objetivos promover o desenvolvimento sustentável, atingindo um equilíbrio entre as dimensões econômica, ambiental e social, consideradas como significativas na composição desta temática.

É justamente com relação à dimensão social que se questiona, neste artigo, a existência de uma metodologia consolidada, que garanta sua adicionalidade nos projetos de Mecanismo de Desenvolvimento Limpo (MDL).

Dessa forma, intenta-se discutir elementos que ampliem a percepção das necessidades e contribuam para o avanço da incorporação da dimensão social, sob a ótica da sustentabilidade, nos projetos do MDL, mais especificamente ligados ao escopo de biogás de aterro sanitário, objeto empírico escolhido para esta pesquisa.

Para tanto, a abordagem das capabilities será utilizada como principal orientação teórica neste artigo, justamente por apresentar princípios relacionados à dimensão social e o estudo/histórico dos indicadores sociais como métodos de medida de seu desenvolvimento.

A abordagem das capabilities foi escolhida como orientadora por apresentar contribuições para uma nova compreensão dos conceitos sobre miséria, fome, pobreza e bem-estar social. Provavelmente por conviver e observar a discrepância da realidade de seu país em comparação com os países desenvolvidos, Sen (2000;2001), que enunciou a abordagem das capabilities, aprofundou seus estudos na economia dos países em desenvolvimento e em sua relação com as condições de vida das populações mais desfavorecidas.

O estudo dos indicadores sociais será importante para comprovar que, apesar da difícil trajetória no estabelecimento dos critérios, há diretrizes e indicações que podem ser definidas para trazer maior objetividade às avaliações de cunho social.

\section{A abordagem das capabilities}

A partir da análise da questão social Sen (2000;2001) chegou à conclusão de que a desigualdade deve ser considerada como elemento crucial na avaliação da questão social e, justamente por isso pode oferecer contribuição significativa para análise de critérios relativos ao desenvolvimento social referente à política do Protocolo de Kyoto e da avaliação dos projetos do Mecanismo de desenvolvimento Limpo.

Avaliando o tema da desigualdade de forma mais precisa, apresentou uma nova perspectiva, que pode ser entendida tanto a nível macro (pensando na diferenciação entre desenvolvidos e não desenvolvidos) quanto a nível micro (relacionando os proponentes e investidores dos projetos de MDL e as comunidades por eles afetadas). 
Assim, Sen pontua principalmente duas linhas de avaliação da igualdade - os igualitaristas de renda e os igualitaristas de bem-estar - para fundamentar a idéia de que mesmo sendo os teóricos destas vertentes considerados igualitaristas, suas visões, além de diferentes, podem ser consideradas inclusive opostas. Para o primeiro grupo a questão da igualdade centra-se na questão da renda, sendo a solução para o problema da desigualdade obtida por meio do estabelecimento de rendas não tão díspares. Para o segundo grupo, o foco está no nível de bem-estar que, independente da renda, deveria ser igual para todos.

A partir deste exemplo o autor demonstra que a questão não se centra na discussão tradicional de um grupo contra o outro com relação à abordagem correta da igualdade. Segundo Sen (2001), cada grupo adota visões tendenciosas por considerarem determinados aspectos mais importantes que outros, de acordo com sua abordagem particular, desconsiderando a diversidade e a preferência humana.

Em uma visão inovadora, o autor abandona os tradicionais enfoques de igualdade e adota uma abordagem onde as liberdades substantivas e a possibilidade de as pessoas utilizarem-nas de acordo com suas preferências são determinantes para o desenvolvimento e para a busca da igualdade nas sociedades.

Em sua obra "Desigualdade reexaminada", Sen (2001) coloca em questionamento diversas percepções anteriores à sua de igualdade social e concentra-se no questionamento "igualdade de que?", observando que a desigualdade é freqüentemente avaliada sob diferentes olhares, dependendo do que se pretende como resposta. Dessa forma, o autor afirma que a avaliação de desigualdade fica comprometida por principalmente duas diversidades. A primeira diz respeito à própria heterogeneidade básica do ser humano, no que se refere principalmente às características que os desassemelham, diferem e distinguem, o que torna a avaliação da desigualdade complexa e de difícil comparação. A segunda principal dificuldade é a multiplicidade de variáveis em cujos termos a igualdade pode ser julgada. Neste sentido são investigados justamente como definir e quais critérios devem ser utilizados para o embasamento da avaliação da igualdade.

Por conta desses dois elementos (vinculados principalmente à percepção de valor atribuído às variáveis pelas pessoas) que enviesam inevitavelmente a avaliação da desigualdade e possibilitam a construção de incontáveis modelos desse tipo de avaliação, estabelecer critérios aceitos universalmente como essenciais torna-se uma tarefa impraticável.

Assim, se determinado grupo (que compartilha uma visão) selecionar variáveischave (denominadas por Sen como variáveis focais) que limitem a abordagem do tema em um dado contexto, estará sendo designado um "espaço de avaliação" que seria crucial para analisar a desigualdade, que estaria inevitavelmente subordinada àquele olhar e, portanto contrária a outros. Assim, afirma Sen (2001, p.51): "uma das consequências da diversidade humana é que igualdade num "espaço de avaliação" tende a andar, de fato, junto com a desigualdade em outro". 
É por isso que a padronização de um modelo de avaliação que aborde a questão da desigualdade de uma forma completa é impossível de ser realizado. Esta dificuldade, apresentada na teoria de Sen (Ibidem), está fundamentalmente vinculada à questão do bem-estar e às relações entre capacidades (capabilities), funcionamentos (functionings) e realizações (achievements).

Essas capacidades representam as várias combinações de funcionamentos que a pessoa pode realizar, ou seja, as oportunidades e liberdades para escolher entre os diversos funcionamentos. Os funcionamentos, por sua vez, são ações ou estados de bem-estar (não necessariamente realizados), escolhas ou o conjunto de escolhas disponíveis para a realização do bem estar. Como exemplo de funcionamentos relevantes o autor destaca alguns como estar adequadamente nutrido, gozar de boa saúde, poder escapar de mortalidade prematura, ou até mesmo estar feliz, ter autorrespeito ou fazer parte da vida da comunidade. Assim, de acordo com Sen (2001), os funcionamentos não são instrumentos para realizar bem-estar, mas sim que os funcionamentos fazem parte dos elementos constituintes do bem-estar.

Esse conjunto de opções, quando efetivadas constroem a realização (ou parte dela) daquele indivíduo. Assim a realização é vetor dos funcionamentos, ou seja, é fruto dos funcionamentos realizados pela pessoa.

Comotanto as capacidades, quanto os funcionamentos ea realização são elementos que, quando existentes na vida das pessoas, aparecem de forma particularmente diferente, não é possível estabelecer um modelo onde se possa produzir um ambiente onde exista consenso com relação à forma de utilização das liberdades substantivas (que existem em diversos níveis) para a produção de bem-estar (que é percebido de maneiras específicas pelos indivíduos).

Tornando ainda mais complexo o exame da desigualdade, é certo, para Sen, que para que qualquer análise seja justa, independente da variável focal admitida, é preciso considerar as diferenças existentes entre os avaliados. Nesse sentido Sen considera diversas distinções: (1) as oportunidades de realização e as realizações de fato; (2) os funcionamentos e capacidades ligadas principalmente à questão do bem estar; (3) a utilização da liberdade como liberdade de condição de agente e/ou liberdade de bem estar; (4) a questão da justiça aliada às capacidades, partindo das contribuições de Ralws, particularmente do princípio das diferenças; (5) a questão econômica como forma de determinar o bem-estar, com abordagem especial à pobreza e à baixa renda e (6) a inserção social do indivíduo.

Em sua obra "Desenvolvimento como liberdade" (SEN, 2000), originalmente publicado sete anos após "Desiqualdade reexaminada" (SEN, 2001), o autor concentrase em demonstrar que o desenvolvimento pode ser visto como um processo de expansão das liberdades reais que as pessoas desfrutam. Sua abordagem contrasta com visões mais restritas de desenvolvimento, como por exemplo a da proposta de mensuração de crescimento pelo aumento do Produto Interno Bruto (PIB). Considera também limitadas as abordagens que focalizam unicamente em suas avaliações 
critérios como o aumento da renda pessoal, industrialização e avanço tecnológico. (SEN, 2000;2001)

Sen (2000) apresenta diversas formas de privação de liberdades como fomes coletivas, não obtenção de nutrição adequada, a carência de serviços públicos e de saúde, ou a negação de participação política e civil por regimes autoritários e acredita que com a aquisição das liberdades que pontua, seja possível um processo real de desenvolvimento das sociedades.

No breve comentário realizado por Sen em "Desenvolvimento como liberdade" (2000) com relação aos desafios ambientais, é colocada a importância da alocação dos recursos tidos como "bens públicos" onde se deve considerar não só a possibilidade da ação do Estado e da provisão social, mas principalmente as garantias de transparência como a ética ambiental, o desenvolvimento de valores sociais e o senso de responsabilidade para com o meio ambiente.

No artigo "Porque é necessário preservar a coruja pintada?" publicado pela Folha de São Paulo (SEN, 2004), Sen aponta algumas relações presentes em seu pensamento com a questão do desenvolvimento sustentável. Aponta a responsabilidade cívica considerando a cidadania ambiental e a formação do cidadão ecológico como um papel importante a ser explorado para a promoção do cuidado com o ambiente e do desenvolvimento sustentável. $O$ autor assinala também que a responsabilidade associada ao poder, refletida como um valor humano é também um fator significativo para esta contibuição e pontua que o fato de sermos seres humanos, e, portanto, mais poderosos do que as demais espécies, nos torna responsáveis por seu cuidado e bem estar. É neste caso que cita o exemplo da coruja pintada justificando o porquê devemos protegê-la da extinção.

Reconhece também que o desenvolvimento da auto-responsabilidade e a capacidade de raciocinar e de construir julgamentos - qualidades consideradas por Sen como carentes na sociedade - poderiam suscitar a emergência, sustentação e compreensão das dificuldades e prioridades relativas à questão ecológica.

Sen (2000) critica a adoção de qualquer perda de liberdade como política necessária para lidar com a questão ambiental. Considera a liberdade de participação como um bem valioso que não pode ser perdido nesta construção e lembra, como exemplo da falta de oportunidade de discussão pública por parte dos cidadãos norte-americanos, quando da decisão do presidente George W. Bush em abandonar abruptamente o Protocolo de Kyoto. Critica também a coerção sobre decisões da vida privada das pessoas, pois considera que se forem necessárias tais práticas e cita como exemplo a restrição da liberdade de reprodução como imposta pela China - para atingir os objetivos ambientais, tais perdas já afetam a realização da própria questão da sustentabilidade.

Para o autor, se as liberdades instrumentais forem respeitadas e fornecidas às pessoas, estas buscarão atingir o que entendem por bem estar, constituindo uma sociedade onde a igualdade é principalmente avaliada com relação às liberdades 
usufruídas pelos indivíduos que poderão efetivamente moldar seus destinos e participar ativamente do desenvolvimento da sociedade ao invés de serem vistos como beneficiários passivos de engenhosos programas de desenvolvimento.

\section{Indicadores sociais}

Considerando a perspectiva de Sen com relação à desigualdade e ao desenvolvimento da sociedade, a construção de indicadores de desenvolvimento enfrenta um dilema de difícil solução.

Por um lado sua tese caracteriza-se pela impossibilidade de sistematizar uma estrutura que contenha critérios que respeitem a heterogeneidade dos indivíduos, de seus valores e de suas liberdades usufruídas e que resulte em valores quantitativos quanto ao desenvolvimento das sociedades. Por outro lado, não oferecer um indicador de desenvolvimento adequado e simplesmente adotar a abordagem de Sen como uma teoria não resulta em uma solução satisfatória.

Diante deste dilema, o autor parece ter escolhido por não "contradizer" sua teoria já que apesar de criticar a avaliação de desenvolvimento por meio do PIB pois considera este método incompleto e irreal para avaliar o que se propõe - não menciona, em nenhum momento, sua intenção de criar novos parâmetros para tal - até porque considera que qualquer tipo de construção neste sentido não reflete a avaliação tal como deve ser ${ }^{1}$.

No entanto, apesar de compreender este dilema, o economista paquistanês Mahbub ul Haq (PNUD, 1990) adotou uma postura diferente de Sen. Para ele, mesmo considerando a dificuldade em estabelecer critérios de desenvolvimento que refletissem de fato a realidade das diferentes sociedades (principalmente com relação às privações e as liberdades substantivas dos indivíduos) era de fundamental importância construir uma nova forma prática de abordar a questão do desenvolvimento que suplantasse a hegemonia do PIB com relação à avaliação do desenvolvimento (PNUD, 1990).

Convencido de que as sociedades buscavam uma maneira conveniente de avaliar o desenvolvimento - e que esta conveniência estava na época fundamentalmente apoiada no PIB - Mahbub ul Haq, que inspirou-se nas reflexões apontadas por Sen, idealizou o IDH (Índice de Desenvolvimento Humano), que seria a estruturação um índice sintético como o PIB, composto de somente um número, mas que atentasse não somente para o crescimento quantitativo, mas que considerasse aspectos sociais da vida humana (PNUD, 1990).

Assim, o IDH é composto de principalmente três indicadores: longevidade, educação e renda per capita. Apesar de seus próprios idealizadores entenderem que este índice não seria nada mais do que um indicador de desenvolvimento bastante limitado, os principais méritos do IDH, para eles, foram, em primeiro lugar, oferecer uma nova medida que não fosse tão limitada quanto o PIB e em segundo lugar de 
fomentar o interesse público para o Relatório de Desenvolvimento Humano, do qual Mahbub foi idealizador, que foi publicado pela primeira vez em 1990, pelo Programa de Desenvolvimento das Nações Unidas (PNUD, 1990). O IDH é apresentado como parte deste relatório que compõe, segundo Sen uma rica coleção de informações e apresenta a complexa realidade da sociedade por meio de características sociais, econômicas e políticas que influenciam a natureza e a qualidade de vida humana. Desde o início das publicações, além dos dados básicos, em cada um dos relatórios foram adotados enfoques específicos que estão relacionados ao desenvolvimento humano. O Relatório de 2007/2008, por exemplo, teve como norteador a questão ambiental, sob o título "Combater a mudança do clima: Solidariedade Humana em um mundo dividido" (PNUD, 2007).

Depois do IDH, já foram idealizadas diversas outras tentativas de medir o desenvolvimento das sociedades. Veiga (2009) aponta a iniciativa do presidente francês Nicolas Sarkozy de convidar os detentores de prêmios Nobel de economia Joseph Stiglitz e Amartya Sen para que propusessem uma alternativa de superação do PIB e do IDH. Assim, em 2008, foi criada a Comissão para Mensuração da Performance Econômica e do Progresso Social que ficou conhecida como Comisão Stiglitz-SenFitoussi, por serem seus principais representantes.

Apesar de não terem sido atendidas as expectativas de que a Comissão StiglitzSen-Fitoussi faria uma proposta concreta de outro indicador sintético que pudesse medir simultaneamente o desenvolvimento e a sustentabilidade, as recomendações apresentadas no relatório final contribuíram positivamente, para "o processo que levará - em um futuro certamente distante - a uma maneira consensual de se medir avanços e recuos no rumo do desenvolvimento sustentável" (VEIGA, 2009a, p.5).

O relatório final, publicado em junho de 2009, resultado do trabalho de três subgrupos da Comissão que focaram, respectivamente, nos temas desenvolvimento sustentável e meio ambiente, desempenho econômico e qualidade de vida, produziu, segundo Veiga (2009), esclarecimentos sobre quais são os principais obstáculos para a construção de novos indicadores e mostrou o que precisará ser feito para que possam ser superados. Para saber como poderá ser monitorado o desenvolvimento sustentável, as respostas do relatório final da Comissão podem ser sintetizadas em três tópicos.

O primeiro diz respeito a ser bem pragmático sobre a sustentabilidade. Este olhar de praticidade promovido pela Comissão, de acordo com Veiga (2009), é derivado de uma abordagem onde o termo "sustentável" é adotado não como um adjetivo, que se referia à necessidade de que o processo socioeconômico conservasse suas bases naturais ou sua biocapacidade, mas sim como um substantivo, inserindo a idéia de componentes não-biofísicos da sustentabilidade. Assim, ao invés de somente enfatizar a imprescindível sustentabilidade ambiental do processo que se costuma chamar de desenvolvimento ou de progresso social, passa-se a tratá-la ao lado de várias outras dimensões, como a econômica e a social. 
O exemplo mais aparente desta relação refere-se justamente às contribuições do subgrupo responsável pelo tema "Desenvolvimento Sustentável e Meio Ambiente" que foi, segundo Veiga (2010, p.49), enfatizar que "qualquer indicador monetário de sustentabilidade deve permanecer focado apenas em seus aspectos estritamente econômicos" e que "os aspectos propriamente ambientais da sustentabilidade devem ser acompanhados pelo uso de indicadores físicos bem escolhidos". O recado, conclui Veiga (2009), é bem claro: buscar bons indicadores não-monetários da aproximação de níveis perigosos de danos ambientais.

O segundo tópico sintetizado pelo relatório está relacionado à questão da qualidade de vida. Diferente da primeira sugestão relacionada à sustentabilidade, a proposta aqui é de "ampliar o leque". A comissão sugere que todo o acúmulo já existente sobre avaliações subjetivas de bem-estar seja incorporado em avaliações de qualidade de vida.

O terceiro e último item, superar a contabilidade produtivista, está mais diretamente ligado a transpor os problemas clássicos relacionados ao uso do PIB como medida de desenvolvimento. Assumindo como inevitável a criação de novas medidas, no futuro, afirma Veiga (2009), parecerá inacreditável que por meio século o progresso social tenha sido medido pela produção bruta per capita e que só a partir de 1990 tenha passado a sofrer concorrência de uma simplória média aritmética, num "tosco" índice de desenvolvimento humano.

Como contribuição ao avanço de indicadores mais realistas e eficazes, o relatório oferece cinco recomendações diretas e incisivas:

“1) olhar para renda e consumo em vez de olhar para a produção; 2) considerar renda e consumo em conjunto com a riqueza; 3 ) enfatizar a perspectiva econômica; 4) dar mais proeminência à distribuição de renda, consumo e riqueza; 5) ampliar as medidas de renda para atividades não-mercantis" (VEIGA, 2009a, p.4).

O relatório observa, segundo relato de Veiga (2009), que para que se tenha um verdadeiro balanço da economia nacional é preciso considerar os ativos presentes em uma nação como o capital físico/construído, capital humano/social e capital natural/ ecológico. Uma inovação proposta pelo relatório é a avaliação líquida e não bruta das atividades econômicas, de modo que as extrações de recursos naturais, os impactos ambientais gerados pela produção ou a utilização de estoques sejam levadas em conta.

Veiga (2009) afirma que estabelecer um único indicador capaz de revelar simultaneamente o grau de sustentabilidade do processo socioeconômico e o grau de qualidade de vida que dele decorre "provavelmente nunca surgirá", justamente pela impossibilidade de expressar de maneira reducionista a complexidade do que seria a contribuição para a manutenção dos processos evolutivos da biosfera, que envolvem, em um sentido ainda mais amplo, os fatores biofísicos, psicológicos, econômicos e socioculturais entrelaçados na idéia de desenvolvimento sustentável. 
No entanto, buscando maior precisão, os idealizadores de indicadores passaram a adotar abordagens cada vez mais regionalizadas. É o caso do Índice DNA Brasil que intenta verificar a realidade nacional e do Índice Paulista de Responsabilidade Social (IPRS), focado nos municípios do Estado de São Paulo. (NEPP, 2006)

O Índice DNA Brasil foi idealizado pelo Núcleo de Estudos de Políticas Públicas (Nepp) da Unicamp em conjunto com o Instituto DNA Brasil e aborda, em uma tentativa de evitar o reducionismo contido nos índices sintéticos, um conjunto de indicadores selecionados de aspectos da realidade social, econômica, cultural e demográfica brasileira. Essas dimensões são: (1) Bem-estar econômico; (2) Competitividade econômica; (3) Condições sócio-ambientais; (4) Educação; (5) Saúde; (6) Proteção social básica; (7) Coesão social. Cada uma dessas dimensões, por sua vez, é composta de diversos subitens, que ao todo somam 24 indicadores. A proposta inicial de apresentação dos resultados foi na forma gráfica de "estrela", que representava entre 0,0 e 1,0 o desenvolvimento do Brasil com relação a cada um dos indicadores. A proposta do Índice DNA Brasil é fundamentalmente a de balizar a movimentação de atores públicos e privados envolvidos em projetos de desenvolvimento. Esta avaliação se dá por meio da visualização da realidade brasileira a partir de comparações do próprio Brasil em relação às expectativas de futuro e à situação de outros países.

Para esta avaliação foram selecionados 45 participantes da sociedade brasileira. Este grupo, no entanto parece não ter agradado os pesquisadores da Unicamp que no artigo "O Índice DNA Brasil" afirmaram que tais participantes, "demonstrando quanto o reducionismo está enraizado em nossa forma de pensar, pediram que o resultado fosse também apresentado na forma de um único 'número'" (BIASOTO ET $A L, 2008$, p.5). Assim, apesar da tentativa de evitar que a complexidade brasileira fosse reduzida a um único número, que não seria capaz de apontar os desequilíbrios nestas dimensões, os pesquisadores brasileiros viram-se em uma situação semelhante à de Sen com relação ao IDH e ao Relatório de Desenvolvimento Humano e renderam-se ao cálculo da média dos 24 indicadores.

No caso do Índice Paulista de Responsabilidade Social (IPRS, 2009), elaborado para analisar o desenvolvimento e a qualidade de vida nos municípios paulistas, o sistema de apresentação dos resultados passou pelo mesmo desafio: combinar as dimensões adotadas de forma a não subvalorizar nenhuma delas e tampouco apresentá-las de tal forma a permitir uma interpretação equivocada sobre a avaliação de algum dos aspectos.

Dessa forma, os idealizadores do IPRS da Fundação Seade, opondo-se ao modelo de média aritmética optaram por apresentar os resultados por meio de quatro indicadores: três setoriais e uma tipologia (IPRS, 2009). Os indicadores setoriais referem-se a três eixos que foram baseados nos aspectos que compõem o IDH, mas adotam diferentes variáveis no intuito de atingir um indicador que evidencie maiores diferenciações entre as diversas situações socioeconômicas observadas nos municípios paulistas. Cada um dos três eixos setoriais: riqueza municipal, longevidade 
e educação, são compostos por componentes que possuem diferentes pesos e juntos somam $100 \%$ de cada um dos indicadores sintéticos, que são mensurados em uma escala de 0 a 100 (IPRS, 2009). Sob a ótica de Sen, seria questionável o critério adotado para o estabelecimento dos diferentes pesos já que esta pode ser somente uma percepção, um olhar, que considera um fator mais significativo do que outro com relação à riqueza do município, longevidade ou educação. Provavelmente, diria Sen, sob a perspectiva de um determinado grupo de paulistas, os pesos seriam considerados totalmente diferentes dos propostos pelo IPRS.

Enfim, com o resultado da escala é possível a classificação de cada um dos indicadores nos níveis alto, médio e baixo ${ }^{2}$. Dessa forma, é possível a formação da tipologia que resume a situação dos municípios considerando os três eixos e classificando-os em grupos.

No artigo "Indicadores para diagnóstico, monitoramento e avaliação de programas sociais no Brasil", após apresentar-se consciente com relação às diversas críticas aos indicadores sociais sintéticos (construção e aplicabilidade), Januzzi (2005) defende sua legitimidade em diversos aspectos: (1) Social, por conta da visibilidade e freqüência que os indicadores têm conferido às questões sociais na mídia bem como à instrumentalização política do movimento social e das ONGs no monitoramento dos programas sociais; (2) Política, pelo fato de que alguns desses indicadores (como o IPRS) foram criados sob encomenda de gestores público e legisladores; (3) Técnica, por apontarem o que se espera, como por exemplo os bolsões de pobreza e as iniqüidades; (4) Científica, por obterem, em alguns casos, financiamento de agências nacionais e internacionais de pesquisa; e (5) Institucional, por terem servido de instrumento de garantia das instituições de estatística e planejamento em um quadro de forte contingenciamento e de corte de verbas no setor público nos últimos 15 anos.

Mesmo com a consciência das dificuldades de construção e aplicabilidade de indicadores sociais apresentados, tais argumentos justificam o avanço da pesquisa em direção a sua construção. Mesmo que tais métodos ainda não se apresentem cientificamente confiáveis e consolidados, é justamente no processo de pesquisa que se constrói a possibilidade de atingir resultados mais precisos.

\section{Protocolo de Kyoto e perspectiva da dimensão social}

No que diz respeito ao debate em torno da dimensão social na implementação de um mecanismo econômico-climático como o $\mathrm{MDL}$, por orientação do próprio Conselho Executivo do MDL cada AND (Autoridade Nacional Designada) para assuntos relacionados ao $\mathrm{MDL}$, deve estabelecer critérios adicionais a fim de contribuir para os objetivos do mecanismo. A princípio, a AND só deveria aprovar os projetos que atendessem aos critérios internacionais do artigo 12 do Protocolo de Kyoto (BRASIL MCT, 2001b) e aos nacionais por ela estabelecidos para depois enviá-los para a avaliação do Conselho Executivo. 
Segundo as exigências da Comissão Interministerial de Mudança Global do Clima - que é a AND brasileira - para serem considerados elegíveis no Brasil, além dos requisitos do Protocolo de Kyoto, os projetos de MDL devem: (1) promover o desenvolvimento sustentável ambiental local, avaliando a mitigação dos impactos ambientais locais (resíduos sólidos, efluentes líquidos, poluentes atmosféricos, dentre outros) propiciada pelo projeto em comparação com os impactos ambientais locais estimados para o cenário de referência; (2) Melhorar as condições de trabalho e a geração líquida de empregos relacionados ao compromisso do projeto com responsabilidades sociais e trabalhistas, programas de saúde e educação e defesa dos direitos civis bem como ao incremento no nível qualitativo e quantitativo de empregos (diretos e indiretos) comparando-se o cenário do projeto com o cenário de referência; (3) Fomentar distribuição de renda a partir da avaliação dos efeitos diretos e indiretos sobre a qualidade de vida das populações de baixa renda, observando os benefícios socioeconômicos advindos da atividade do projeto; (4) Contribuir para capacitação e desenvolvimento tecnológico relacionados ao grau de inovação tecnológica do projeto em relação ao cenário de referência, às tecnologias empregadas em atividades passíveis de comparação com as previstas no projeto e a possibilidade de reprodução da tecnologia empregada; e por fim (5) a integração regional e articulação com outros setores que pode ser medida a partir da integração do projeto com outras atividades socioeconômicas na região de sua implantação. (BRASIL. MCT, 2008).

Alguns desses requisitos acabam sendo cumpridos naturalmente, por derivarem de condições obrigatórias para a realização do projeto. A geração líquida de empregos e a distribuição de renda são os melhores exemplos dessa situação já que para que o projeto ocorra é imprescindível a contratação de pessoal. Outros itens como contribuir para capacitação, integração regional e articulação com outros setores ficam difíceis de mensurar e, na prática, são apreciados quando apresentados, mas não vem sendo considerados como critérios classificatórios ou eliminatórios na avaliação da elegibilidade.

O mesmo vem acontecendo com outros dois componentes - a sustentabilidade e a dimensão social - que, por sua expressividade, extrapolam quaisquer fronteiras documentais, são difíceis de mensurar e não tem determinado - assim como outros "requisitos obrigatórios" - a aprovação ou a reprovação do projeto como atividade do MDL.

Em se tratando do primeiro componente - a sustentabilidade - o relatório Worldwide Fund for Nature (2007) evidenciou sua preocupação com o fato de que o desenvolvimento sustentável é muitas vezes negligenciado, e sugeriu que esta situação foi provavelmente agravada pelo fato de que o Conselho Executivo do MDL não previu critérios comuns para a contribuição de um projeto para o desenvolvimento sustentável (WWF-UK, 2007, p.7). De fato, apesar de ser um objetivo do MDL "assistir às Partes não incluídas no Anexo I para que atinjam o desenvolvimento sustentável" não houve, de fato, uma publicação que instruísse os proponentes quanto aos critérios e 
requisitos práticos indicados como necessários para que os projetos contribuíssem a este objetivo.

Esta consideração, porém, resgata as complexas reflexões sobre o conceito de sustentabilidade. Ora, se não há concordância conceitual de como medir a sustentabilidade, como seria definir critérios definitivos, capazes de negar a aprovação de um projeto com o argumento de que "não contribuía ao desenvolvimento sustentável"?

Considerando o envolvimento da questão da sustentabilidade neste contexto e visando o equilíbrio decorrente deste direcionamento nos projetos de $\mathrm{MDL}$, o segundo componente - o social - assume a posição de objeto de investigação de maior importância, tendo em vista o fato de ser o aspecto menos maturado - se comparado com as dimensões ambiental e econômica - no MDL. Diversas discussões sobre metodologias, adicionalidade, validação etc. com relação aos aspectos econômicos e ambientais vinculados aos projetos de MDL já foram fomentadas e até desgastadas. Com relação à questão social, no entanto, não houve um debate sério e profundo em relação a tais aspectos o que tornou o conceito de desenvolvimento sustentável difuso nesta dimensão.

O relatório "Progress Toward Developing Sustainability Criteria for the Clean Development Mechanism" apresentado pelo Programa em Ciência e Política Ambiental da Universidade de Columbia (GALLARDO e ANDERSON, 2004), enfatiza que apesar de cada país ser responsável por desenvolver os seus próprios critérios de sustentabilidade, existem, no entanto, "algumas áreas gerais que todos os países devem incorporar aos seus critérios de projeto." (Ibidem). No que diz repeito à área social o relatório esclarece que os projetos devem contribuir para melhorar a qualidade de vida nos países envolvidos e incluir a participação ativa de todos os interessados.

Com relação a este segundoaspecto de contribuição comaárea social, o Documento de Concepção do Projeto (DCP) reserva um item especial para que os proponentes dos projetos demonstrem a intenção de envolver as comunidades e outras partes no processo. O item "comentários das partes interessadas" ou "Stakeholder's coments" é o quinto dos cinco pontos propostos para a apresentação do DCP e inclui como subitens "breve descrição de como foram solicitados e compilados os comentários das partes interessadas locais", "síntese dos comentários recebidos" e "relatório sobre como foram devidamente considerados os comentários recebidos" (UNFCCC, 2011, p. 30). Assim, a limitada contribuição de "consultar as partes interessadas" parece ser a única contribuição social diretamente solicitada na apresentação dos projetos de MDL.

Como forma de auxiliar esta análise, as contribuições presentes na abordagem de Sen (2001) podem ser consideradas como significativas por apresentarem ricas estruturas interdependentes entre as dimensões econômica e social, tendo a função de orientar em "como pensar a questão social". (Sen, 2000; 2001) 
Para a análise e contribuições ao Protocolo de Kyoto para a dimensão social, interessa entender da questão social e do pensamento de Sen: (1) A subjetividade nas avaliações da questão social; (2) O desenvolvimento social e a riqueza de uma sociedade não estão necessariamente vinculados única e exclusivamente ao crescimento econômico e distribuição de renda; (3) O desenvolvimento social inclui diversos aspectos que relacionam-se a liberdades, escolhas e oportunidades que entre outros, norteiam a aquisição e utilização da renda e que portanto são mais decisivos do que a própria renda.

Para pensar indicadores sociais para o Protocolo de Kyoto são contribuições deste artigo: (1) A identificação da dificuldade de sistematização de métodos de avaliação social - comprovada na observação dos indicadores sociais (PIB, IDH, DNA Brasil e IPRS) que complementaram o estudo com foco no desenvolvimento social; (2) A comprovação de que as propostas de materialização de indicadores apresentam deficiências, mas que também refletem alternativas possíveis para sua realização; (3) Mesmo não refletindo matematicamente a realidade do desenvolvimento social é possível, por meio dos indicadores, apontar uma direção útil com relação às questões atendidas satisfatoriamente e as mais vulneráveis, o que justifica sua aplicação.

\section{Projetos de MDL de biogás de aterro sanitário brasileiros e os padrōes de contribuição social}

Para que a verificação empírica da adicionalidade social nos projetos de MDL do escopo de biogás de aterro sanitário possa ser consistente, é preciso que seja precedida da avaliação dos benefícios da implantação de aterros sanitários - como medida de gestão e disposição dos Resíduos Sólidos Urbanos (RSU) - sem considerar a atividade de projeto do MDL. Isso porque somente tendo clara esta diferenciação é que será possível avaliar efetivamente a presença da adicionalidade social em tais projetos, já que a regra base considerada é que o projeto só é adicional se houver contribuições além das que ocorreriam na ausência do projeto (BRASIL MCT, 2001b; 2001c). Assim, os benefícios a serem considerados como advindos da implantação dos projetos de MDL seriam somente os adicionais aos já existentes pela própria atividade do aterro sanitário.

Considerar, por exemplo, a melhora do saneamento básico por conta do aumento do número de aterros sanitários adequadamente operados bem como a possibilidade de desenvolvimento tecnológico de empresas de saneamento no país como benefícios, só seria viável no caso de os aterros terem sido implantados devido à viabilidade oferecida única e exclusivamente por conta da existência da atividade de projeto de MDL. Dessa forma tais benefícios e a adicionalidade social poderia ser considerada garantida.

No entanto, em nenhum dos 32 projetos avaliados, que representam a totalidade dos projetos de biogás de aterro aprovados no Brasil, foi verificada essa situação. 
Em todos os casos a atividade de projeto do MDL foi proposta em circunstâncias onde os aterros já haviam sido instalados. Dessa forma, benefícios existentes anteriormente à atividade do projeto do MDL como a contenção da degradação do solo, do comprometimento de mananciais, da poluição do ar e dos problemas na saúde pública - que são considerados benefícios decorrentes da própria implantação dos aterros sanitários (BRASIL IBGE, 2000) - não poderiam ser considerados como benefícios da implantação das atividades de projeto do MDL. Com a nova política de resíduos sólidos disposta pela Lei Federal n 12.305/2010 (BRASIL, MMA, 2010), a própria implantação de aterros sanitários passa a ser uma exigência legal e, portanto, reitera a posição de que os benefícios advindos da instalação do aterro não são considerados adicionais por conta do projeto do MDL.

Os benefícios da implantação dos aterros sanitários - independente da existência da atividade do MDL estariam ligados mais diretamente aos fatos de que: (1) evitam a proliferação de moscas, baratas, urubus, outros animais nocivos e outros vetores de doenças à saúde humana; (2) inibem o surgimento de catadores de lixo, contribuindo para a prevenção da condição de saúde dos mesmos; (3) evitam o espalhamento de lixo nas redondezas pela ação do vento; (4) auxiliam no controle de odores fétidos nas áreas de habitação humana; (5) contem a contaminação do solo e das águas superficiais e subterrâneas pelo chorume, que recebe tratamento; (6) alteram as paisagens visuais positivamente onde antes havia "lixões" há céu aberto. (BRASIL IBGE, 2000)

Apesar de serem derivados da própria implantação dos aterros, alguns desses itens são considerados nos Documentos de Concepção dos Projetos (DCPs) ou Project Design Documents (PDDs) como contribuições das atividades de $\mathrm{MDL}$, tendo como principais citados: a contenção dos problemas com a saúde pública - citado em 14 deles e a diminuição dos problemas causados pelo não tratamento do chorume citado em 27 deles (Tabela 1).

Além destes benefícios - que apesar de serem citados pelos proponentes dos projetos não podem ser considerados adicionais por não serem derivados da atividade de MDL - em 25 dos projetos a geração de emprego e renda locais por conta da demanda extra de trabalho decorrente da atividade do MDL é citada como benefício social. Nesse caso, vale fomentar a seguinte discussão: em todas as atividades econômicas que visam lucro é necessária a gestão e a contratação de recursos humanos como elemento fundamental. Sendo assim, a geração de empregos faz parte das necessidades básicas para a existência do projeto e considerá-la como benefício social seria supervalorizar uma conseqüência natural da implantação do projeto.

Como em todos os projetos de MDL avaliados os aterros já eram existentes antes das atividades de MDL, e como no Brasil não há leis obrigatórias quanto à queima tampouco quanto à geração de energia a partir do biogás de aterro, os benefícios a serem considerados como adicionais deveriam ser só e justamente os relativos às atividades de captura, queima e/ou geração de energia. Dentre eles é possível citar: 
Tabela 1 - Benefícios citados nos PDDs como contribuição das atividades de MDL

\begin{tabular}{|c|c|c|c|c|c|c|}
\hline Projeto & $\begin{array}{l}\text { Geração de } \\
\text { empregos }\end{array}$ & $\begin{array}{l}\text { Menor risco } \\
\text { de incendios } \\
\text { e explosões }\end{array}$ & $\begin{array}{l}\text { Saúde } \\
\text { pública }\end{array}$ & $\begin{array}{l}\text { Redução ou } \\
\text { eliminação } \\
\text { odores e do } \\
\text { mau cheiro }\end{array}$ & $\begin{array}{l}\text { Tratamento } \\
\text { do chorume }\end{array}$ & Outros \\
\hline Nova Gerar & $\operatorname{sim}$ & $\operatorname{sim}$ & $\operatorname{sim}$ & $\operatorname{sim}$ & $\operatorname{sim}$ & \\
\hline Vega & não & não & não & não & $\operatorname{sim}$ & \\
\hline Marca & $\operatorname{sim}$ & sim & $\operatorname{sim}$ & sim & $\operatorname{sim}$ & \\
\hline Lara & $\operatorname{sim}$ & $\operatorname{sim}$ & não & $\operatorname{sim}$ & $\operatorname{sim}$ & \\
\hline $\begin{array}{l}\text { ONYX - } \\
\text { Tremembé }\end{array}$ & não & $\operatorname{sim}$ & $\operatorname{sim}$ & $\operatorname{sim}$ & $\operatorname{sim}$ & $\begin{array}{l}\text { Danos a } \\
\text { vegetação } \\
\text { por asfixia }\end{array}$ \\
\hline Estre & $\operatorname{sim}$ & $\operatorname{sim}$ & não & $\operatorname{sim}$ & $\operatorname{sim}$ & \\
\hline Caieiras & $\operatorname{sim}$ & sim & não & $\operatorname{sim}$ & $\operatorname{sim}$ & \\
\hline Bandeirantes & $\operatorname{sim}$ & $\operatorname{sim}$ & não & $\operatorname{sim}$ & não & \\
\hline Anaconda & $\operatorname{sim}$ & $\operatorname{sim}$ & $\operatorname{sim}$ & $\operatorname{sim}$ & $\operatorname{sim}$ & \\
\hline São João & $\operatorname{sim}$ & $\operatorname{sim}$ & não & $\operatorname{sim}$ & não & \\
\hline Canabrava & $\operatorname{sim}$ & $\operatorname{sim}$ & $\operatorname{sim}$ & sim & $\operatorname{sim}$ & \\
\hline Aurá & $\operatorname{sim}$ & $\operatorname{sim}$ & não & $\operatorname{sim}$ & $\operatorname{sim}$ & \\
\hline $\begin{array}{l}\text { Embralixo- } \\
\text { Araúna }\end{array}$ & $\operatorname{sim}$ & $\operatorname{sim}$ & $\operatorname{sim}$ & $\operatorname{sim}$ & $\operatorname{sim}$ & \\
\hline Sil-Probiogás & $\operatorname{sim}$ & $\operatorname{sim}$ & não & $\operatorname{sim}$ & $\operatorname{sim}$ & \\
\hline Manaus & $\operatorname{sim}$ & $\operatorname{sim}$ & $\operatorname{sim}$ & $\operatorname{sim}$ & $\operatorname{sim}$ & \\
\hline Alto-Tietê & $\operatorname{sim}$ & $\operatorname{sim}$ & $\operatorname{sim}$ & $\operatorname{sim}$ & $\operatorname{sim}$ & \\
\hline $\begin{array}{l}\text { Terrestre/ } \\
\text { Progata }\end{array}$ & $\operatorname{sim}$ & $\operatorname{sim}$ & não & $\operatorname{sim}$ & não & \\
\hline $\begin{array}{l}\text { Estre Itapevi/ } \\
\text { Progae }\end{array}$ & $\operatorname{sim}$ & $\operatorname{sim}$ & não & $\operatorname{sim}$ & não & \\
\hline $\begin{array}{l}\text { Quitauna- } \\
\text { Progaq }\end{array}$ & $\operatorname{sim}$ & $\operatorname{sim}$ & $\operatorname{sim}$ & $\operatorname{sim}$ & $\operatorname{sim}$ & \\
\hline $\begin{array}{l}\text { Pedreira- } \\
\text { Progaep }\end{array}$ & $\operatorname{sim}$ & $\operatorname{sim}$ & não & $\operatorname{sim}$ & não & \\
\hline Santech & $\operatorname{sim}$ & $\operatorname{sim}$ & $\operatorname{sim}$ & $\operatorname{sim}$ & $\operatorname{sim}$ & \\
\hline Probiogás-JP & $\operatorname{sim}$ & $\operatorname{sim}$ & não & não & $\operatorname{sim}$ & \\
\hline $\begin{array}{l}\text { Tijuquinhas da } \\
\text { Proactiva }\end{array}$ & $\operatorname{sim}$ & $\operatorname{sim}$ & $\operatorname{sim}$ & $\operatorname{sim}$ & $\operatorname{sim}$ & $\begin{array}{l}\text { Danos a } \\
\text { vegetação } \\
\text { por asfixia }\end{array}$ \\
\hline Uapbiogás & não & $\operatorname{sim}$ & não & $\operatorname{sim}$ & $\operatorname{sim}$ & \\
\hline Vila Velha & não & $\operatorname{sim}$ & $\operatorname{sim}$ & $\operatorname{sim}$ & $\operatorname{sim}$ & \\
\hline $\begin{array}{l}\text { Feira de } \\
\text { Santana }\end{array}$ & não & $\operatorname{sim}$ & não & $\operatorname{sim}$ & $\operatorname{sim}$ & \\
\hline Gramacho & não & não & não & não & $\operatorname{sim}$ & \\
\hline Tecipar-Progat & $\operatorname{sim}$ & não & não & $\operatorname{sim}$ & $\operatorname{sim}$ & \\
\hline CTRS - BR040 & $\operatorname{sim}$ & $\operatorname{sim}$ & não & não & $\operatorname{sim}$ & \\
\hline Aterro de Natal & $\operatorname{sim}$ & $\operatorname{sim}$ & $\operatorname{sim}$ & $\operatorname{sim}$ & $\operatorname{sim}$ & \\
\hline Corpus Araúna & não & $\operatorname{sim}$ & não & $\operatorname{sim}$ & $\operatorname{sim}$ & \\
\hline $\begin{array}{l}\text { Aterro de } \\
\text { Manaus }\end{array}$ & $\operatorname{sim}$ & $\operatorname{sim}$ & $\operatorname{sim}$ & $\operatorname{sim}$ & $\operatorname{sim}$ & \\
\hline RESULTADOS & 25 & 29 & 14 & 28 & 27 & 2 \\
\hline
\end{tabular}

Elaboração: Autores 
(1) a redução de odores incômodos do ar relativos ao biogás liberado - citado em 28 projetos; (2) a diminuição dos riscos de explosões e incêndio - comentado em 29 projetos; (3) a inibição dos riscos de asfixia e/ou efeitos tóxicos em espaços confinados com altas concentrações de gases de aterro - considerado em 2 projetos (Tabela 1).

Além disso, oito projetos prevêem a destinação de parte da renda da venda dos créditos de carbono - que vai de $2 \%$ a $5 \%$ - a projetos sociais na comunidade do entorno sendo que três deles - projetos Santech, Vila Velha e Gramacho - não citam a porcentagem a ser destinada. Desses, somente cinco - Vega, Lara, Caieiras, Anaconda, Embralixo/Araúna - citam os projetos e as contribuições específicas a serem realizadas com a porcentagem da renda destinada. Outros três - Marca, Estre, Alto/Tietê citam também as contribuições específicas e os projetos sociais previstos, mas não apresentam claramente que os projetos serão realizados com parte da renda da venda dos créditos de carbono.

Na avaliação empírica dos projetos de biogás de aterro sanitário comprovou-se que as contribuições sociais são também pouco significativas. Verificou-se que nos 32 DCPs dos projetos de biogás de aterro sanitário já aprovados no Brasil a preocupação com a questão social é muito mais citada pró-forma do que propriamente para a construção de benefícios adicionais e efetivos para a sociedade do entorno dos aterros. Tais contribuições podem ser resumidas como: (1) adota-se como benefício social a geração de emprego e renda por conta da execução do projeto; (2) considerase que a própria realização do projeto traz benefícios sociais; (3) é estabelecida uma porcentagem do retorno financeiro advindo dos créditos de carbono (normalmente entre 1 e $2 \%$ ) a ser destinado a atividades sociais nas comunidades residentes no local de implantação do projeto.

Do total de nove projetos ${ }^{3}$ que apresentam a contribuição social específica, seis deles já estavam com os projetos em andamento antes da proposta da atividade de projeto do MDL. Nesses casos as contribuições aconteciam como projetos de responsabilidade social vinculados às empresas privadas proponentes dos projetos de MDL e a proposta, no geral, é que com a atividade do MDL os programas sociais possam ser fortalecidos.

Os três projetos que se propõem a iniciar as contribuições sociais a partir de parte da receita advinda da venda dos créditos de MDL e que citam a porcentagem a ser destinada são o Projeto de Biogás de Aterro em Energia no Aterro da Lara, em Mauá SP, o Projeto de redução de emissão do aterro da Central de Tratamento de Resíduos Vila Velha (CTRVV), em Vila Velha - ES, e o Projeto Gramacho de Biogás de Aterro, em Duque de Caxias - RJ. Somente estes, se avaliada a rigor a questão da elegibilidade no sentido de ter a ação social proporcionada pela atividade de projeto, seriam de fato considerados como adicionais. 


\section{Conclusão}

Os mecanismos de atuação desenvolvidos pelo Protocolo parecem tratar a questão do desenvolvimento social como uma conquista natural advinda dos resultados ambientais materializados a partir da atuação econômica, e não como um tema tão importante quanto os demais na busca de uma equalização.

Especificamente na dimensão social não há sequer definição de exigências mínimas tampouco de critérios classificatórios ou eliminatórios na avaliação da adicionalidade. Tal subvalorização foi constatada não somente nos documentos oficiais do Protocolo de Kyoto e do MDL como também na avaliação empírica dos projetos de biogás de aterro sanitário. As comparações referentes ao fundamento do aporte teórico determinado (com relação à abordagem das capabilities e dos indicadores sociais) com os projetos de biogás de aterro sanitário são apresentadas na Tabela 2.

Assim, de acordo com as verificações teóricas e empíricas, elaborar métodos e construir instituições capazes de estabelecer claramente as contribuições nas diferentes dimensões parece ser o gargalo e, portanto, o ponto central para a avaliação da questão social nos projetos do MDL. Inicialmente a questão é entender a interdependência, e o principal desafio parece ser encontrar um trade off aceitável, que seja eficaz nos objetivos sociais, ambientais e econômicos.

Neste sentido, pragmaticamente seriam dois os pontos principais a serem considerados em um contexto geral: (1) a apresentação, pelo Conselho Executivo do MDL e/ou pela Autoridade Nacional Designada, de um método prático que estabelecesse claramente o que se pretende e o que se entende por contribuição social nos projetos de MDL bem como de manuais detalhadamente desenhados que direcionem os proponentes na construção de tais propostas sociais; (2) tendo estabelecido tais estruturas e objetivos, expor as exigências e a linha base do processo de verificação e monitoramento das ações sociais.

Com isso seria possível questionar, logo de início, não só a inexistência das propostas sociais como também o nível de envolvimento existente. Com tal orientação e tendo clareza do que é considerado como contribuição social ao projeto, os proponentes poderiam então ser cobrados com relação a uma perspectiva e propostas objetivas e posteriormente o monitoramento quanto a sua implementação. Assim, a deficiência com relação às contribuições sociais apresenta-se claramente não só como um problema relacionado à falta de comprometimento dos proponentes dos projetos no que diz respeito à questão social, como também (e talvez principalmente) com relação à organização da Comissão Executiva do MDL e da Autoridade Nacional Designada. Se as funções das autoridades reponsáveis são, dentre outras, oferecer direcionamento para a realização dos objetivos propostos pela Convenção Quadro das Nações Unidas para o Meio Ambiente (CQNUMA) e pelo MDL, tornam-se elementos indispensáveis determinar os requisitos de uma proposta de contribuição social, apoiar os proponentes em sua realização por meio de orientações publicadas em relatórios e manuais e exigir o cumprimento do proposto. 


\begin{tabular}{|c|c|c|c|c|c|c|}
\hline 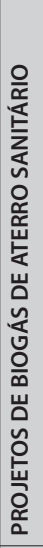 & 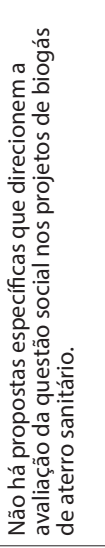 & 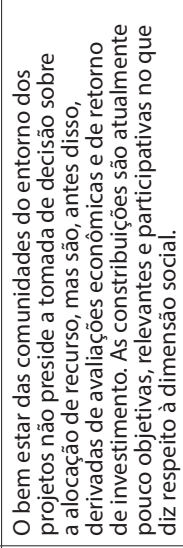 & 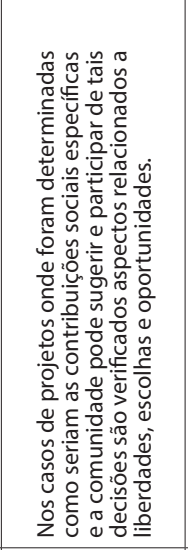 & 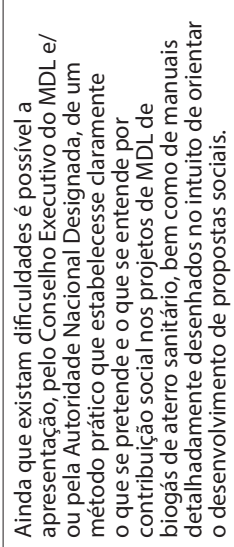 & 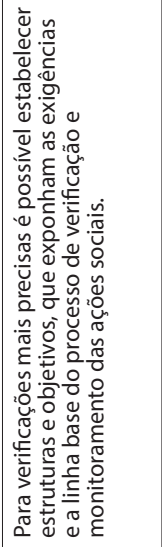 & 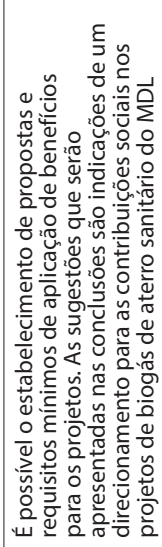 \\
\hline 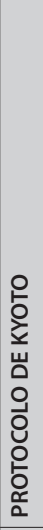 & 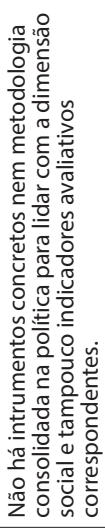 & 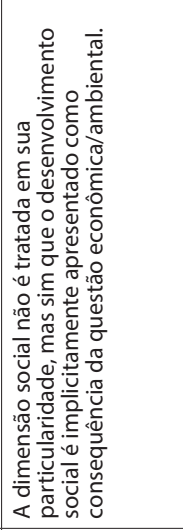 & 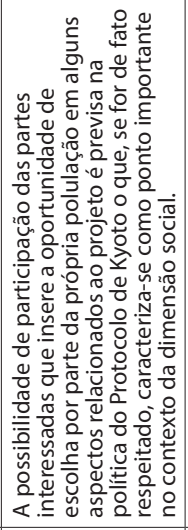 & 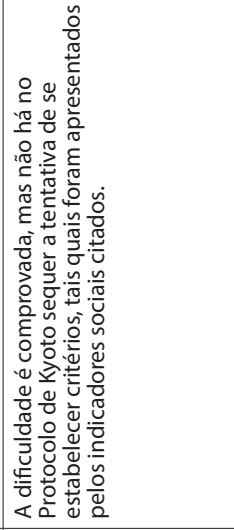 & 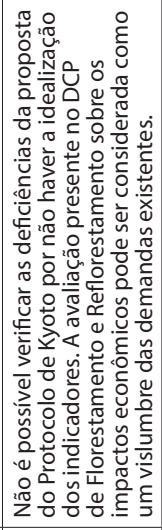 & 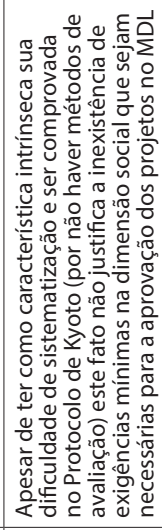 \\
\hline$\frac{\tilde{U}}{\tilde{U}}$ & 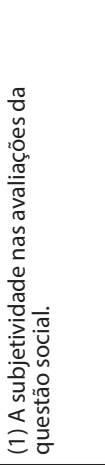 & 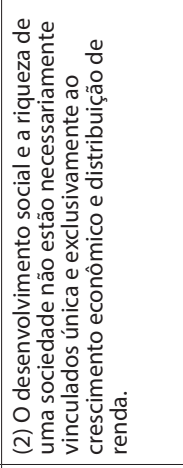 & 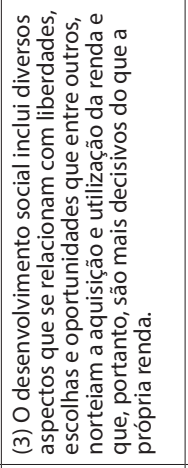 & 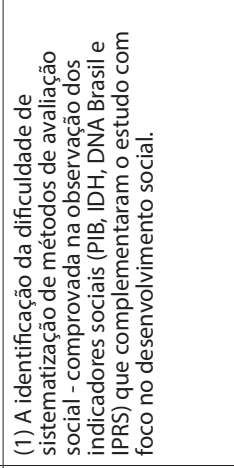 & 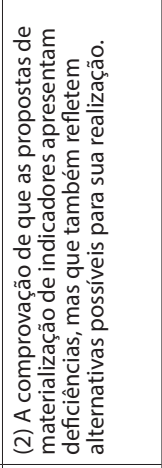 & 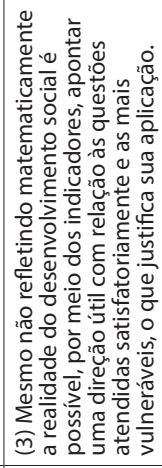 \\
\hline 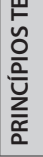 & & 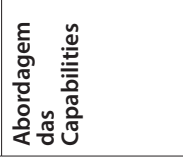 & & & 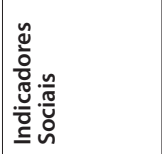 & \\
\hline
\end{tabular}


Neste sentido sugere-se: (1) Que haja suporte financeiro para que se estabeleça uma estrutura capaz de construir benefícios efetivos no campo social, destinando obrigatoriamente porcentagem da renda da venda dos créditos de carbono a ações junto à comunidade local (tanto implantação como manutenção) por todo o tempo previsto pelo projeto; (2) O desenvolvimento de um diagnóstico profundo e detalhado acerca da realidade social da comunidade circundante aos projetos; (3) A existência de um projeto pré-estabelecido e determinado com a efetiva participação dos indivíduos quanto ao destino dos investimentos e a flexibilidade de reavaliação frente às demandas apresentadas no planejamento e na execução do projeto; (4) Que os projetos garantam a possibilidade de longevidade dos benefícios do projeto para o indivíduo/comunidade beneficiada, contribuindo para a realização permanente do bem estar social; (5) Que haja rigor na determinação dos benefícios sociais sendo considerados somente quando adicionais aos já existentes pela própria atividade do aterro nos métodos de avaliação social a serem desenvolvidos nos projetos deste escopo.

As reflexões que aqui foram apresentadas - que mostram a urgência e a necessidade de não negligenciarmos as questões sociais - expõem a oportunidade de transformação coletiva, que é, na verdade, o conjunto de opções individuais que quando se encontram e se assemelham, produzem resultados positivos. Insistir em ignorar a situação ou refazer uma nova lógica tão ignorante quanto a anterior, seria atestar, de fato, nossa falta de valores humanos. Mas ao que se têm apresentado em diversas áreas do conhecimento, alguns passos tem sido dados em direção a uma racionalidade mais ampla e abrangente, mesmo que ainda existam posturas arraigadas que defendem e dificultam tal movimento de abertura.

\footnotetext{
Notas

' Em 2008 Sen retoma esta crítica e participa da Comissão para Mensuração da Performance Econômica e do Progresso Social (conhecida como Comisão Stiglitz-Sen-Fitoussi) da qual foi um dos principais representantes. Os resultados do relatório da Comissão, que são apresentados mais adiante neste mesmo artigo, corroboram a posição de Sen, por não oferecerem indicadores de avaliação de maneira sistematizada e sintética, mas sim indicações de elementos necessariamente presentes na avaliação dos avanços relativos aos temas da proposta.

2 O corte (baixa média e alta) acompanha a evolução/involução dos municípios. Os parâmetros de definição dos valores mínimos e máximos dos três indicadores sintéticos não são relativos, mas estabelecidos segundo os valores normativos ou referentes ao período de 1992 a 1997 (Apêndice Estatístico) e atualizados conforme a necessidade. (IPRS, 2004)

${ }^{3}$ Verificou-se que em todos os projetos que apresentam contribuições sociais específicas a proposta de apoio social está, entre outras atividades, vinculada principalmente à educação ambiental e treinamentos que envolvem a questão do lixo. Independente do nível de envolvimento social de cada um dos projetos, tais contribuições apresentaram-se de alguma forma vinculadas ao escopo do projeto.
} 


\section{Referências bibliográficas}

BIASOTO, G; GIOVANNI, G; DACHS, N; SILVA, P.L.B. 2009. O Índice DNA Brasil. Disponível em http://cienciaecultura.bvs.br/pdf/cic/v58n2/a02v58n2.pdf. Acesso em 20/01/2009.

BRASIL. IBGE. Instituto Brasileiro de Geografia e Estatística. 2000. Pesquisa Nacional de Saneamento Básico. Disponível em http://www.ibge.gov.br/home/estatistica/populacao/ condicaodevida/pnsb/pnsb.pdf. Acesso em 05/09/2012

- Protocolo de Kyoto. 2001b. Editado e traduzido pelo Ministério da Ciência e Tecnologia com apoio do Ministério das Relações Exteriores da República Federativa do Brasil. 2001b. Disponível em http://www.mct.gov.br/upd_blob/0012/12425.pdf. Acesso em 20/10/2009.

.Decisão 17/CP.7. 2001c. Modalidade e procedimentos para um mecanismo de desenvolvimento limpo, conforme definido no Artigo 12 do Protocolo de Kyoto. Disponível em http://www.mct.gov.br/upd_blob/0004/4955.pdf. Acesso em 20/10/2009.

BRASIL. MMA - MINISTÉRIO DO MEIO AMBIENTE. 2010. LEI No 12.305. Disponível em http://www. mma.gov.br/port/conama/legiabre.cfm?codlegi=636. Acesso em 25/04/2009

CCAP. Center for Clean Air Policy . 2012. Disponível em www.ccap.org. Acesso em 16/02/2012

GALLARDO, Rodolfo. ANDERSON, Kristin. Progress Toward Developing Sustainability Criteria for the Clean Development Mechanism. 2004. Disponivel em http://www.roger-raufer.com/ Columbia_2004_CDM_SD.pdf. Acesso em 15/02/2015

IPRS. Índice Paulista de Responsabilidade Social: Metodologia. 2009. Disponível em http://www. seade.gov.br/produtos/iprs/pdf/metodologia.pdf Acesso em 04/11/2008.

. Índice Paulista de Responsabilidade Social: Informativo. 2004. Disponível em http://www. seade.gov.br/produtos/iprs/pdf/informativo.pdf. Acesso em 04/11/2008.

JANUZZI, P M. 2005. Indicadores para diagnóstico, monitoramento e avaliação de programas sociais no Brasil. Revista do Serviço Público Brasília 56 (2): 137-160 Abr/Jun 2005.

NEPP. 2006. Núcleo de estudos de políticas publicas da Universidade Estadual de Campinas. Projeto Índice DNA Brasil. Disponível em http://www.nepp.unicamp.br/dnabrasil/ referenciadnabrasil2006.pdf. Acesso em 13/02/2009.

PNUD. Programa das Nações Unidas para o Desenvolvimento. 1990. Relatório do Desenvolvimento Humano. Disponível em http://hdr.undp.org/sites/default/files/reports/219/ hdr_1990_en_complete_nostats.pdf Acesso em 30/01/2009.

. Programa das Nações Unidas para o Desenvolvimento. 2007. Relatório do Desenvolvimento Humano. Disponível em http://www.pnud.org.br/arquivos/rdh/rdh20072008/ hdr_20072008_pt_complete.pdf. Acesso em 30/01/2009.

SEN, Amartya. 2000. Desenvolvimento como Liberdade. São Paulo: Companhia das Letras. . 2001. Desigualdade Reexaminada. Rio de Janeiro: Record, 2001. . 2004 Por que é necessário preservar a coruja pintada. Folha de São Paulo, 14 mar 2004, Caderno Mais, p. 16

UNFCCC. United Nations Framework Convention on Climate Change. 2011. Guidelines for users of the joint implementation land use, land-use change and forestry Project design document form. Disponível em http://ji.unfccc.int/Ref/Documents/LULUCF_Guidelines_(version_02).pdf Acesso em 03/14/2012.

.2008. CDM EB. Executive Board. Tool for the demonstration and assessment of additionality. EB 39 Report. Annex 10. Disponível em http://cdm.unfccc.int/methodologies/ PAmethodologies/tools/am-tool-01-v5.2.pdf Acesso em 04/07/2011 
VEIGA, José Eli. Mundo em transe: do aquecimento global ao ecodesenvolvimento.

São Paulo:Armazém do Ipê, 2009.

- Trindade para monitorar o desenvolvimento sustentável. 2009a Disponivel em http://www.fea.usp.br/feaecon/media/fck/File/[jev]\%20-\%20Trindade\%20monitorar\%20DS\%20 -\%2004out09.pdf Acesso em 23/02/2015 - Indicadores de Sustentabilidade. Estudos Avançados. vol.24 no.68. São Paulo. 2010

WWF-UK. 2007. Emission impossible: acess to J//CDM credits in phase Il of the EU Emissions Trading Scheme. Diponível em http://www.wwf.org.uk/wwf_articles.cfm?unewsid=2394. Acesso em 22/09/2008. 